\section{The Architectural Teaching Paradox The Practice-Based PhD as a Compass in Navigating through the Incommunicable}

Cecilia De Marinis

Deakin University

Dorotea Ottaviani Virginia Tech

\section{INTRODUCTION}

The reflections developed in this paper took place from a sentence that architect Botta pronounced during the conference 'The Practice of Teaching' held at the Biennale Architettura 2018 - 16th International Architecture Exhibition. In that context Botta stated "It is not possible to teach architecture, but it is possible to learn architecture"1. This statement unveils the paradox inherent in architectural education on two different levels of reflection: first, reveals a truth about the different facets of architectural education that can be taught such as history, theory, technology etc., whereas the practice of architecture itself cannot be actually taught. The second stage of the refle tion reveals an even more interesting feature of architectural education: design and the design practice are in fact taught but we do not have a clear understanding of how the process happens.

Such anomaly suggests the existence of a nebulous space between teaching and learning in architecture and multiple questions arise from such reflections: how can one teach the matter of design? ow is operational knowledge transferred from teachers to learners? Can one be trained on how to transfer knowledge or can one rely solely on their innate hunch?

\section{THE ISSUE OF KNOWLEDGE TRANSFER IN THE TEACHING PRACTICE}

Those questions show a puzzling reality about the fact that we do teach architecture but there are no precise rules for doing it nor one way to do it. This unstructured condition comes from the fact that architecture and all design disciplines don't deal with certainties nor with a one-size-fits-all approach to solutions due to their xplorative nature, where the outcome is the result of contextual conditions, challenges, and personal attitudes. The way in which creative practice can become proper research relies on rigorous methodology and shared values within their community of practice. Findeli suggested that design relates on values and rigour rather than truth, meaning that in the teaching for the design practices the spotlight is on learning "how" rather than "what".

Therefore, in this system of both implicit and explicit rules governing the discipline, the way in which one teaches and transfers operational knowledge becomes pivotal. The hardest challenge in the practice of design teaching is, therefore, how to make students aware not only of the prescriptive rules but especially of the implied ones and of the ethical repercussions of every step in the decision-making process of design.

In this scenario of unprescribed rules and uncertain directions the task for the design teacher is, thus, a rather difficult one, $h$ ving the responsibility to communicate an obscure and often incommunicable matter to students.

Subsequently, as Schön states making "clear to one another what it is they do when they design" is the core of what happens in the design studio ${ }^{3}$. 


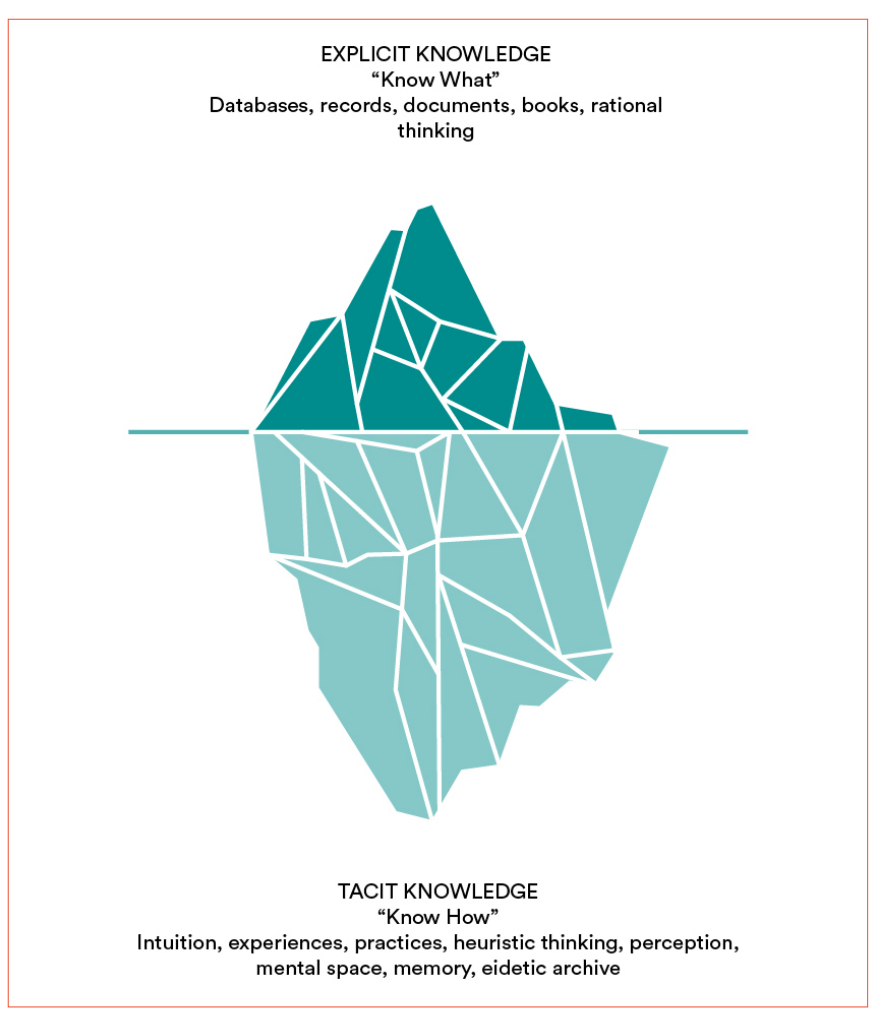

Figure 1. Knowledge Iceberg Model Diagram. (Credits: C. De Marinis, D. Ottaviani)

What we have outlined so far, this difficult process of $t$ anslation from the teacher's own hunches to the students, can be better described by the concept of tacit and explicit knowledge.

With knowledge we generally refer to a familiarity, awareness or understanding of someone or something. The understanding of a topic that can be gained as facts, information, descriptions, or skills, can be usually acquired through experience or education by perceiving, discovering, or learning. Knowledge can refer to the theoretical understanding of a subject and it is usually described either as explicit, as with the theoretical understanding of a subject, or implicit or tacit, which is a kind of knowledge that is difficult to $t$ ansfer to another person by means of writing it down or verbalizing it.

Tacit knowledge is the $\mathrm{fl}$ xible and dynamic realm of knowledge which is hard to grasp being possibly undetected and below the surface of what clearly organized and taught through theoretical or doctrinal knowledge.

The well-known iceberg metaphor shows the binomial relationship between knowing "what", the explicit knowledge and knowing "how", the tacit part, which can refer to intuition, experience, practice, heuristic thinking, perception, mental space, memory, eidetic archive and other unstructured ways of grasping reality (Figure 1).

In the context of design knowledge, it becomes clear how this research of the "how" pursues very different path from the research of a generalised and globally accepted "truth". Glanville articulates that design epistemology addresses the mess and the "swampy lowland" since it traverses unknown landscapes, without knowing where to go but led from an inner intuition based on the designer's tacit knowledge ${ }^{4}$. This path is then constellated "with scientific and non-scientific $k$ wledge, with fuzzy and outdated knowledge, and with no knowledge at all, in order to achieve these value-laden fits. The art of muddling through' or, more positively, of 'informed intuition', should not be scorned, but seen as a core element of design" as affirmed y Jonas ${ }^{5}$.

For these reasons, the most challenging task for the design teacher lies here, in the transfer of their own tacit knowledge to their students, articulating it through words or other media.

Furthermore, this process becomes even more problematic since design teachers often address such a challenging task without a proper and formal training but relying on their own hunch and intuition about how to teach, learning how to do it while practicing the teaching itself.

\section{THE ROLE OF THE DESIGN TEACHER}

The task of the design teacher is a hard one due to the complex and multifaceted nature of the practice of architecture and its extensive relying on implicit kind of knowledge ${ }^{6}$.

Design teachers have to articulate what the matter of design is and clarify what it is that they are actually doing when they design ${ }^{7}$, making explicit the tacit knowledge ${ }^{8}$ embedded in their practice.

The role of the design teacher has many possible articulations: they can be a master ${ }^{9}$ whose word and work is admired and emulated by students; a mentor able to generate a conversation and emotional engagement with students, which flourishes in trust and requires hared values and time to be developed ${ }^{10}$; a guide, guiding students in their own cyclic process of making, testing, changing, refining; an instructo supporting students in the familiarisation process into the professional community and culture ${ }^{11}$; an empowerer providing students with tools to interpret, explore and transform the given circumstances rather than create more or less masterful buildings, focusing on the critical understanding of the design process rather than on its outcomes ${ }^{12}$; lastly, a coach helping students in reflecting on what th $y$ are doing to solve problems.

The performance of each articulation informs accordingly the relationship between student and has a considerable impact on the learning process.

\section{THE PRACTICE-BASED PHD PROGRAM}

As part of our research on the practice-based $\mathrm{PhD}$ we noted that PhD candidates reported a sense of betterment in their teaching practice ${ }^{13}$. Hence, we want to bring attention to the relevance of the practice-based $\mathrm{PhD}$ as a training for teaching in design disciplines, revealing how it could be considered as a possible answer to acquire and improve teaching abilities.

The practice-based $\mathrm{PhD}$ is an original investigation undertaken 
through designing and producing new knowledge by means of practice and exploring modes of practice while practicing. In this context, practice is studied as an 'activity' rather than an 'object'14 since reflectio for practitioners is something that happens in action ${ }^{15}$.

This $\mathrm{PhD}$ is concerned with the nature of practice itself, including all its multifaceted aspects such as designing, teaching, and researching, and produces knowledge that has operational significance th $t$ can be employed directly in the practice itself.

In this manner, teaching, as one of the aspects of practice, is simultaneously object and method for the inquiry.

One of the goals of the practice-based PhD is to make explicit and communicable what lies on the implicit level of the practice, therefore, it can foster hermeneutics of the practice helping the communication between teacher and students.

There are several interpretations of how a practice-based PhD might be pursued. In this research we refer to the program established at RMIT University (Melbourne, AU). Such program, developed over the last 20 years, served as reference for numerous other universities in Australia and Europe.

This PhD model is articulated in a three-year program where candidates are invited to present their research twice a year in a colloquium with their supervisors, peers, and the community at large, called PRS (Practice Research Symposium). The PRSs are semi-public events that represent the space and time for the academy and industry to gather over common research, the structure has consolidated through the years to the current configu ation that opens the first $d y$ with examinations of completing candidates and continues with milestone and in-progress presentations.

These symposia are the intermediate steps that articulate the one-toone dialogue between the candidate and the supervisor, expanding the discussion towards the community, with its feedback and opinions.

The uniqueness and relevance of the PhD lays on its primary aim of bridging the gap between the academy and the practice. We can trace the distinctiveness of the program in its collegiality that builds on the ecology of its community of practice.

\section{RESEARCH FRAMEWORK AND METHODOLOGY}

Since 2015, we have studied the methodology of Practice-based PhD program developed by RMIT University as part of two inter-institutional research programs: ADAPT-r ${ }^{16}$ and DAP_r ${ }^{17}$.

ADAPT-r (acronym for Architecture, Design and Art Practice Training-research) was an Initial Training Network funded by the EU 7th Framework Programme, that linked the academic and professional realms. The programme - involving 7 partner institutions, 33 early stage research fellows and 7 experienced researchers - was structured across 3 years (2013- 2016) and organised through 6 Practice Research Symposia (PRS), two per year (RMIT Europe, Barcelona and KU Leuven, Ghent).
A final xhibition at the University of Westminster (UK) showcased research produced by PhD candidates and meta-research on the practice-based methodology generated by the post-doc researchers involved in the ADAPT-r network. The project aimed to facilitate the adoption of the practice-based PhD model across Europe and to provide a practice-based doctoral training to creative practitioners, helping to educate new researchers, increasing supervisory capacity and creating new collaborations ${ }^{18}$. The program was funded with over $€ 4$ millions by the European Union through the Seventh Framework Programme FP7/2007-2013, Marie Curie Actions.

DAP_r (Design and Architecture Practice Research) was an inter-institutional research project examining and mobilising a practice-based approach to doctoral research and training in design and architecture. As a collaboration of 14 Australian universities led by RMIT University, the Commonwealth-funded project was active in 2016-2017, and brought together partners from across disciplines to explore the applicability of the model in varied institutional contexts, developing allied supervisory resources, and capitalising on nascent pedagogical scholarship. In 2016 and 2017, DAP_r partners fully participated in the Practice Research Symposia held at RMIT (Melbourne, AU). In addition, the project staged a series of exhibition and symposium events around the country, exploring and showcasing varying approaches to and challenges within creative practice research.

During these two projects we developed a research methodology relying on ethnographic methods including: structured and semi-structured interviews, focus groups, and direct observations of the practice-based PhD process during the presentation at the PRSs, and fieldwork activities

We interviewed more than 50 people amongst PhD candidates, completed PhD and PhD supervisors from different institutions in Europe and Australia. During this research we asked candidates mainly on three aspects: the exploration of Tacit Knowledge ${ }^{19}$, Practice-based Research Methods ${ }^{20}$, and the contribution of the PhD training to the teaching practice ${ }^{21}$.

\section{CONCLUSIONS: THE CONTRIBUTION OF THE PRACTICE-BASED PHD TO DESIGN STUDIO TEACHING PRACTICE}

The analysis and comparison of data collected through the above-presented research operations, led us to identify several threads showing and classifying the contributions that the practice-based PhD can bring to the practice of teaching.

One of the aspects most highlighted by participants, when discussing if and how the PhD improved their teaching practice, 
is the one of a deeper awareness and clarity of their design processes. As a consequence of the reflecti e nature of such an inquiry system, candidates developed a greater awareness of their practicing methods and techniques. Their hunches and urges surface and become actionable elements both in teaching and practice. The meta-level perspective developed during the PhD enables candidates to focus on their design processes as well as on the outcomes.

Researching into their practice can be a tool for teachers to unveil and strengthen the knowledge embedded in the practice and systematise that knowledge into a research framework. Furthermore, this path might lead to an increased awareness of their practice of teaching, and a greater understanding of what the matter of design is and how to articulate it to students.

Awareness and clarity help teachers in making clear to students their own design processes and explaining the reasons behind decisions and directions. Moreover, observing their own design processes and understanding how they work for them, gives teachers the ability to understand how they can work for others and makes. This newly acquired meta-level of understanding, makes them more capable to sustain and guide students' learning development.

Deeper awareness also leads to more self-confidence, another of th aspects emphasised by candidates. A robust confidence deri es from the clarity in articulating what their practice is and by the consciousness of their position within their communities of practice and society. The PhD is structured in a way that invites candidates to present their reflections, doubts, and ongoing outco es to an audience that can be defined as "Community of Practice"22. Benefit ng from the several occasions in which they are required to talk about their practice, candidates cultivate new and more coherent ways of talking about their work, not only to clients, with the goal to persuade them, but also to peers to actually make evident their research and methods. This new ability would then affect their relationship and communication with the students.

Increased confidence and wareness also help teachers in engaging with experimentation, openness, and uncertainty. This opening up to the ability to guide students off the beaten track.

The iteration of publicly presenting twice a year and to keep the conversation going with their supervisors, together with writing, train teachers in better articulating their research and practice to students.

The last, but not least, element valued as a contribution of the $\mathrm{PhD}$, is the discovery for candidates of new pedagogical strategies, experienced through the PhD process, that they can translate into their teaching practices. Candidates found interest in translating the reflecti e model that they learned and experimented during the $\mathrm{PhD}$ into their teaching environment, prioritising a pedagogy of 'reflectio \& research' over one of 'skills \& training'.

In conclusion, as a result of the transformative nature of the prac- tice-based PhD, candidates are provided with a newly repurposed set of tools to navigate through the incommunicable aspects of teaching architecture. Therefore, even though the practice-based PhD is not intentionally nor formally structured to purely be a training for teachers, this research unveiled how this PhD model can actually help in training design teachers.

\section{FUTURE DIRECTIONS OF THE RESEARCH}

Within the field of design pedagog , the growing interest in the topic of training for design studio teaching and the emerging debates over ways of training, point out the relevance of investigating and possibly formalising methods and practices for studio teaching.

It is well known that so far training for teachers has traditionally happened through non-formal ${ }^{23}$ ways such as mentoring and pairing new teachers with more expert academic members.

Interest in formalising training for design teachers has recently increased as shown by the establishment of trainings addressing architectural pedagogies, within academic institutions.

As a way of example, among others, is to be mentioned the two-day workshop "Teaching the Teachers | Education = Key" organised in Tilburg, The Netherlands in March 2019, by Fontys Academy for Architecture and in cooperation with the Education Academy of the EAAE (European Association for Architectural Education).

The themes covered were: "design process; making explicit; experimentation; guiding theme; frame of references; learning a complex skill"24, clearly aligned with the relevant aspects emerged from the analysis of the contribution of the practice-based PhD to teaching practice.

Therefore, a possible future direction of the research that the authors are interested in pursuing, is mapping and analysing how training for design teachers is happening both formally and informally in the European academic context and to what extent the methodological contribution of the practice-based $\mathrm{PhD}$ can inform future training for teachers.

\section{Notes}

1. Botta, Mario. "Biennale Architettura 2018 - Meetings on Architecture 06, The Practice of Teaching”. Filmed [October 2018]. Youtube video, 1:44:57. Posted [October 2018]. \ https://www.youtube.com/watch?v=twVuUP9qO8E.

2. Findeli, Alain. "Rethinking Design Education for the 21th Century: Theoretical, Methodological and Ethical Discussion". Design Issues volume 17, issue 1 (2001), 5-17. https://doi. org/10.1162/07479360152103796 
3. Schön, Donald. The Design Studio. Exploration of its Traditions and Potential. London: RIBA Publications Limited, 1985.

4. Glanville, Ranulph. "Building a Community of Practice, Tallinn: Public Lecture at EAA". Filmed [April 2014]. Vimeo video, 1:11:04. Posted [April 2014]. https://vimeopro. com/artun/building-a-community-of-practice-23042014/ video/103215298.

5. Jonas, Wolfgang. "Exploring the Swampy Ground" In Mapping Design Research, edited by Grand, Simon and Jonas, Wolfgang, 11-42. Basel: Birk user: Basel, 2012.

6. Ferreira, João, Christiaans, Henri \& Almendra, Rita. "A visual tool for analysing teacher and student interactions in a design studio setting". International Journal of CoCreation in Design and the Arts volume 12, issue 1-2: Co-Designing Review Conversations (2016).Pages 112-131.https://doi.org/10.1080 /15710882.2015.1135246.

7. Schön, Donald. The Design Studio. Exploration of its Traditions and Potential. London: RIBA Publications Limited, 1985.

8. Polanyi, Michael. The Tacit Dimension. London: Routledge \& Kegan Paul, 1966.

9. Schön, Donald. The reflective practitioner: How professionals think in action. New York: Basic Books, 1983; Sennett, Richard. The Craftsman. New Haven: Yale University Press, 2008.

10. Oluwole Folorunso, Clement \& Ajulo, Dunsin. "Effect of studio culture on architecture pedagogy in Nigerian universities". Journal of Arts and Sciences.

11. Goldschmidt, Gabriela, Hochman, Hagay and Dafni, Itay. "The Design Studio 'Crit': Teacher-Student Communication." Artificial Intelligence for Engineering Design, Analysis and Manufacturing volume 24, issue 3 (2010). 285-302. https:// doi.org/10.1017/S089006041000020X.

12. Sanford, Kwinter. Rem Koolhaas: Conversations with Students. New York: Princeton Architectural Press, 1996.

13. De Marinis, Cecilia. Design Research Training. The contribution of the practice-based doctoral training on professional practice and pedagogical approaches to Studio Teaching, DAP_r. 2018. Accessed July 26th, 2019. http://dap-r.info/outcomes/ dap-r-research-impact-on-industry-and-pedagogy.

14. Glanville, Ranulph and van Schaik, Leo. "Designing Reflections: Reflections on Design"In Proceedings of the 3rd Doctoral Education in Design Conference, 2003, 35-42. Tsukuba International Congress Centre, University of Tsukuba.

15. Schön, Donald. The reflective practitioner: How professionals think in action. New York: Basic Books, 1983

16. http://adapt-r.eu/. Accessed July 26th, 2019.

17. https://dap-r.info/. Accessed July 26th, 2019.

18. http://adapt-r.eu/partners. Accessed July 26th, 2019.

19. Buoli, Alice, De Marinis, Cecilia, and Ottaviani, Dorotea. Explication of Tacit Knowledge. Deliverable 9 - Collection of Data, ADAPT-r ITN. 2016. Accessed July 26th, 2019. http://radar.gsa.ac.uk/5118/; Buoli, Alice, De Marinis, Cecilia, and Ottaviani, Dorotea. Explication of Tacit Knowledge, Deliverable 10 - Interpretation, ADAPT-r ITN. 2016. Accessed July 26th, 2019. http://radar.gsa.ac.uk/5120/.

20. Buoli, Alice, De Marinis, Cecilia, and Ottaviani, Dorotea. Refinement and Explication of Methods, Deliverable 11 Collection of Data, ADAPT-r ITN. 2016. Accessed July 26th, 2019. http://radar.gsa.ac.uk/5121/0; Buoli, Alice, De Marinis, Cecilia, and Ottaviani, Dorotea. Refinement and Explication of Methods, Deliverable 11b - Interpretation, ADAPT-r ITN. 2016. Accessed July 26th, 2019. http://radar.gsa.ac.uk/5122/.

21. De Marinis, Cecilia. Design Research Training. The contribution of the practice-based doctoral training on professional practice and pedagogical approaches to Studio Teaching, DAP_r. 2018. Accessed July 26th, 2019. http://dap-r.info/outcomes/ dap-r-research-impact-on-industry-and-pedagogy.

22. Lave, Jean and Wenger, Etienne. Situated Learning: Legitimate Peripheral Participation. New York: Cambridge University Press, 1991.

23. UNESCO Institute for Lifelong Learning, 2012 Annual Report. 2012. Accessed July 26th, 2019. https://unesdoc.unesco.org/ ark:/48223/pf0000220310

24. http://www.eaae.be/event/teaching-teachers-education-key/. Accessed July 26th, 2019 